\title{
Application of FVSI, Lmn and CPF Techniques for Proper Positioning of FACTS Devices and SCIG Wind Turbine Integrated to a Distributed Network for Voltage Stability Enhancement
}

\author{
Shaheer Hashim Eisa Osman \\ Department of Electrical Engineering, \\ Pan African University, Institute for \\ Basic Sciences Technology and \\ Innovation, Nairobi, Kenya \\ shaheerkapo2017@gmail.com
}

\author{
George K. Irungu \\ Department of Electrical Engineering, \\ Jomo Kenyatta University of \\ Agriculture and Technology, \\ Nairobi, Kenya \\ girungu@jkuat.ac.ke
}

\author{
David K. Murage \\ Department of Electrical Engineering, \\ Jomo Kenyatta University of \\ Agriculture and Technology, \\ Nairobi, Kenya \\ davidkinyua76@gmail.com
}

\begin{abstract}
Induction power generators are the most popular wind energy conversion systems (WECS) because they do not require synchronization units. However, they usually draw a huge quantity of reactive power during disturbances. Hence, incorporating wind power into power networks may cause voltage instability. This paper presents the usage of STATCOM and SSSC FACTS devices for voltage stability enhancement of a distribution network with a squirrel cage induction generator (SCIG) wind power turbine. The continuation power flow (CPF) approach is utilized as a tool to determine the most suitable position of SCIG in the system. Also, voltage stability indices (FVSI and Lmn) are employed to estimate the stability margin of the system by figuring the weakest transmission lines and buses in order to locate the appropriate position where the FACTS devices should be installed. A comparison of the suitability of the FACTS devices to restore system stability was evaluated under 3phase fault conditions. The results illustrated that STATCOM behaves better than SSSC when the system is restoring from a fault. Simulations and voltage stability assessment were carried out on the IEEE 14 bus test scheme using the PSAT simulation software package.
\end{abstract}

Keywords-squirrel cage induction generator (SCIG); voltage stability analysis; continuation power flow (CPF); voltage stability indices (VSI); STATCOM; SSSC FACTS devices; PSAT

\section{INTRODUCTION}

The integration of wind energy conversion systems (WECS) in electrical power systems can help boosting voltage stability. WECS perform a major role in regulating the electric power flow and enhance the system voltage profiles [1]. Recently, there has been an increase in the use of WECS because the cost of generating electricity using this technology is cheaper compared to other technologies [2]. Currently, several scientific studies have been done on incorporating a squirrel cage induction generator (SCIG) wind power turbine into an electric power system during normal operation and emergencies [3]. By relying on both the wind turbine and operational features of the distribution system, the incorporation of wind power generators can have negative or positive effects on the system's stability and electric power losses $[1,4]$. Therefore, it will be necessary to analyze the influence of the considered SCIG wind power systems with the other electric power system elements. The SCIG was among the first induction generators to be used in wind farms. This generator can also be used in systems with high penetration of wind energy because of features like simple rotor framework and minimal maintenance costs [5]. Operators had experienced many challenges in incorporating wind energy conversion systems in power systems because induction generators always absorb huge amounts of reactive power from the system during normal operation and during disturbances leading to the problem of voltage collapse [5]. Voltage collapse occurs when a significant portion of the system has very low voltage profiles that can lead to an incomplete or overall blackout of the system [6]. In order to alleviate the negative impacts of high-level penetration of the wind power conversion system, various means can be used such as the instalment of FACTS devices which have already been considered as one of the most effective solutions to overcome the voltage stability problem [7]. FACTS devices refer to flexible alternating current transmission systems which can be able to inject or consume reactive power into/from the system [8].

Several researchers have examined the utilization of SCIG wind turbines for various functions corresponding to enhancing voltage profiles and reducing electrical power losses [1] as well as increasing the loadability of the system [7]. The computational continuation power flow technique has been utilized on an IEEE 30 bus test system to find the best position in the wind energy conversion system that will result in system's stability enhancement [9] and to get an appropriate position of STATCOM as indicated in [10]. Various studies have been carried out using numerous voltage stability indices (VSI) such as fast voltage stability index (FVSI), line stability index (Lmn) for several purposes such as determining the 
proper placement of SVC and STATCOM [11], identifying the weakest buses and lines in order to set up FACT devices [12].

The main contributions of the current paper are: (a) The CPF approach is presented to examine the influence of SCIG wind turbine on various regions of the IEEE 14 bus test system for system voltage stability analysis, (b) The FVSI along with Lmn indices are presented for the suitable positioning of STATCOM and SSSC FACTS devices for voltage stability improvement.

\section{WIND ENERGY PLACEMENT}

\section{A. Squirrel Cage Induction Generator (SCIG)}

The SCIG model is driven by a constant speed wind turbine. It is also known as a short-circuit induction generator that could be coupled straight to the electric grid. The configuration and the mathematical equations of the dynamic SCIG wind turbine type are based on the induction motor equivalent circuit $[4,13]$, that could be expressed in a synchronously rotating real-imaginary frame $(\mathrm{r}-\mathrm{m})$ linked with the system reference point angle. Therefore, the maximum power output obtained by the wind power turbine can be expressed mathematically as [13]:

$$
P=\frac{1}{2} \rho S V^{3} C_{p}(\Lambda \beta)
$$

where $\rho$ is the air density, $S$ is the swept area by the wind turbine, $V$ is wind speed, $C_{p}$ defines the performance coefficient, $\Lambda$ is the ratio of tip speed of the turbine blade, and $\beta$ is the pitch angle.

At lower wind speed levels, the performance coefficient relies simply on the ratio of tip speed rather than the pitch angle that would be equal to zero. This coefficient corresponds to the aerodynamic output of the wind turbine providing the highest power output.

\section{B. Continuation Power Flow Method (CPF)}

This particular technique is utilized to measure the maximum loadability point (lambda) of the system. Essentially in CPF technique there are two phases. The first phase, known as the predictor step, is responsible for forecasting the next value of lambda $(\lambda)$ in the case where it shifts from the base condition point. The second step attempts to correct the value which has been forecasted in the initial phase [14]. The purpose of the CPF method is to keep track of the solutions as the loading parameter $\lambda$ varies. This parameter is termed a loading point or (factor) which is utilized to the system MW distance from a primary operating point to the voltage collapse point where the voltages will become critical. The parameter modifies load powers as in [1].

\section{VolTAGE STABILITY INDICES}

There a number of strategies used to assess the system voltage stability which is obtained by the application of indices such as the FVSI index and Lmn index that are capable of identifying the critical lines and corresponding weak buses by measuring the reactive power and voltage of the transmission lines in which the system stability may have been violated [15]. The basic mathematical formulas for FVSI and Lmn employ the general two-bus electric power line model presented in [10].

\section{A. Fast Voltage Stability Index (FVSI)}

The principle behind this index can be illustrated from (2). The more the FVSI is close to 1 in that particular transmission line, the more the system will tend to lose stability.

$$
F V S I=\frac{4 z_{i j}^{2} Q_{j}}{V_{i} X_{i j}} \leq 1
$$

where $Z_{i j}$ is the impedance of the transmission line between bus $i$ and bus $j, X_{i j}$ is the reactance between bus $i$ and bus $j, Q_{j}$ is the reactive power that flows to bus $j, V_{i}$ is the sending-end voltage.

\section{B. Line Voltage Stability Index (Lmn)}

This index is derived by [20]. Upon examination of (3), it can be noted that if the index is $\leq 1$, the system becomes stable otherwise it's unstable.

$$
L_{m n}=\frac{4 X_{i j} Q_{j}}{V_{j}^{2} \sin ^{2}(\theta-\delta)} \leq 1
$$

where $\theta$ is the line angle and $\delta$ is the difference between a sending-end angle and receiving-end angle.

\section{FACTS DEVICES OVERVIEW}

The operation of an alternating current power transmission line is generally limited by the constraints of the electrical power parameters. FACT devices are a novel technology that applies power electronics for controlling voltage, impedance, phase angle, current, active and reactive power during normal and contingency events in order to improve the system controllability, stability and hence increase the power transfer capabilities of the system transmission line. FACTS devices may either be connected in series or shunt. Their behaviors depend on the proper position across the transmission lines and buses. In a two-bus transmission line, the active power and the current flowing through the transmission line can be controlled as stated in $[8,16]$.

\section{A. Static Synchronous Compensator (STATCOM)}

STATCOM is a voltage source converter (VSC) that is connected in parallel to the bus for the purpose of providing dynamic reactive power and thus regulating the system voltage. Both STATCOM and synchronous condenser have the same functionality. They can deliver or consume the reactive power for the system. The basic STATCOM topology can be found in [17]. STATCOM is shunt-connected and therefore functions to control the voltage at the connecting bus with respect to the reference by adjusting the voltage and angle of the internal voltage source. When $E=V$, the reactive current output is zero. When $E>V$, the current will flow to the converter from the $\mathrm{AC}$ system, absorbing reactive power, whereas when $\mathrm{E}<V$, the currents will flow through the converter to the $\mathrm{AC}$ system generating reactive power. When $\delta=0$, the reactive current absorbed $\left(I_{r}\right)$ is given by:

$$
I_{r}=\frac{E-V}{R+j X}
$$




\section{B. Static Synchronous Series Compensator (SSSC)}

SSSC is basically consisting of a VSC, a coupling transformer and a voltage source. The flow of the power can be regulated by controlling the magnitude of the voltage source $\left(V_{c}\right)$ and hence, control the active and reactive power flow in the network. SSSC is connected in series to power transmission lines through a transformer and this is the only difference with STATCOM [17]. The steady-state power in the absence of the energy source between $V_{c}$ and the DC side is shown by:

$$
V_{c} I^{*}=0
$$

This equation illustrates that $V_{c}$ is in quadrature with the flowing current $I$, meaning that there are two operating modes for reactive power compensation (capacitive mode and inductive mode) depending on the phase displacement between the $V_{c}$ and $I$. So, generally

$$
V_{c}^{\wedge}=V_{c}(\cos \gamma-j \sin \gamma) e^{j \emptyset}
$$

where $\gamma$ is the angle by which $V_{c}^{\wedge}$ lags the current, $\emptyset$ is line current phase angle.

\section{DESCRIPTION OF THE SYSTEM MODEL}

In this study, the basic IEEE 14 bus test system as indicated in Figure 1 has been considered.

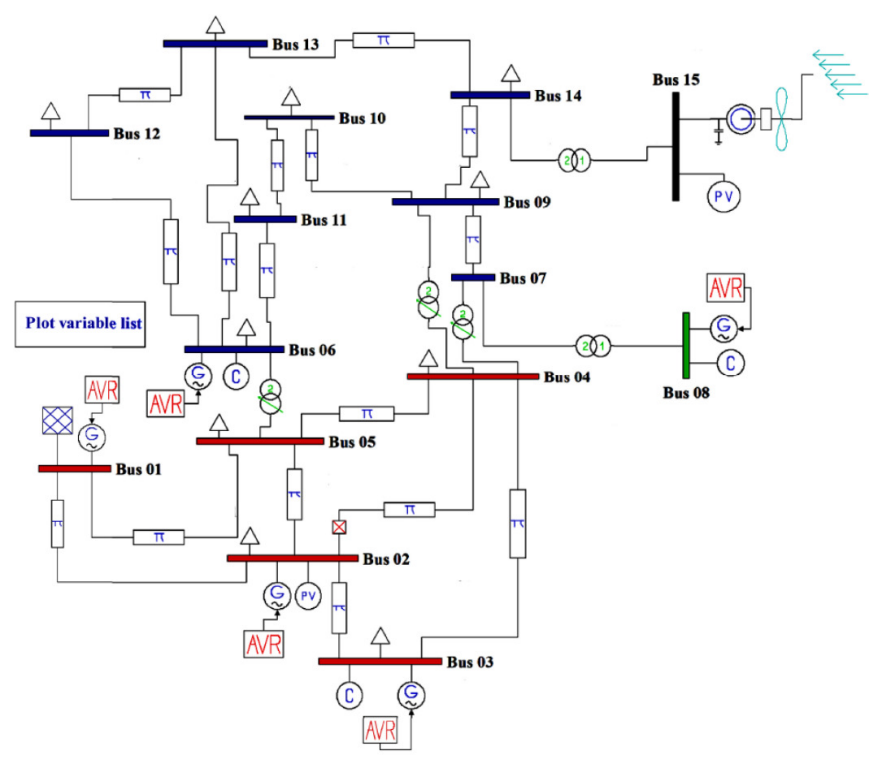

Fig. 1. Illustration of the standard IEEE 14-bus test system with wind incorporated to bus 14

The system comprises of two synchronous power generators, three synchronous condensers, joined together by using numbers of twenty transmission lines to supply eleven load buses [11]. The SCIG model from the PSAT library is employed on this simulation. The chosen MVA and rated frequency are $100 \mathrm{MVA}$ and $50 \mathrm{~Hz}$ respectively. The wind farm comprises of 25 units of $2 \mathrm{MW}, 0.69 \mathrm{kV}, 50 \mathrm{~Hz}$, a SCIG type with $15 \mathrm{~m} / \mathrm{s}$ average wind speed is integrated to the standard IEEE 14 bus system by adding an extra PV bus type at bus 15 through a power transformer. A standard PQ type is utilized for the loads while the generator limitations are dismissed. The SCIG and wind turbine data used in wind farms simulation are found in [18]. The simulation has been executed with the use of PSAT. PSAT is a power system analysis toolbox incorporating various tools such as load flow analysis (LFA), time domain simulation (TDS) and continuation electrical power flow (CPF) [19]. Employing the CPF method of PSAT, the system voltage stability is examined.

\section{SimUlATION, RESUlTS, AND DISCUSSION}

To examine the effects of wind power integration on voltage stability, the simulation was carried out in various stages.

\section{A. Identifying the Proper Location of the Wind Turbine}

In this stage, the SCIG wind power turbine model from the PSAT library was used. The location was identified as an outcome of the CPF approach, on which the system stability was enhanced and electric power losses were minimized. The CPF approach is used to identify voltage levels along with the maximum loadability element of the presented system after introducing the SCIG wind turbine into the system. From the IEEE 14 bus dynamic model base case, a CPF is performed and the voltage profiles were obtained. Figure 2 shows that buses 9 , $10,11,13$, and 14 are the critical buses. Among them, bus 14 is considered the most critical one due to the small value of the voltage profile which is 0.69 p.u.

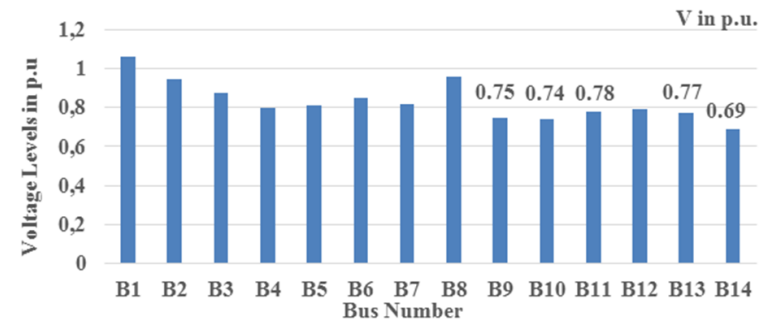

Fig. 2. The voltage profiles of the basic case using CPF method

The active power-voltage (P-V) curve of each bus is obtained through the employment of CPF approach, in which CPF starts with primary operating point and then expanding the load to the maximum loading point. Figure 3 illustrates the P-V curve of each weak bus of the basic case. Maximum loading factor or (point) which is where the Jacobian matrix turns out to be singular, takes place at $\lambda=1.7$ p.u. Bus 14 is demonstrated as the weakest load bus that needs voltage support.

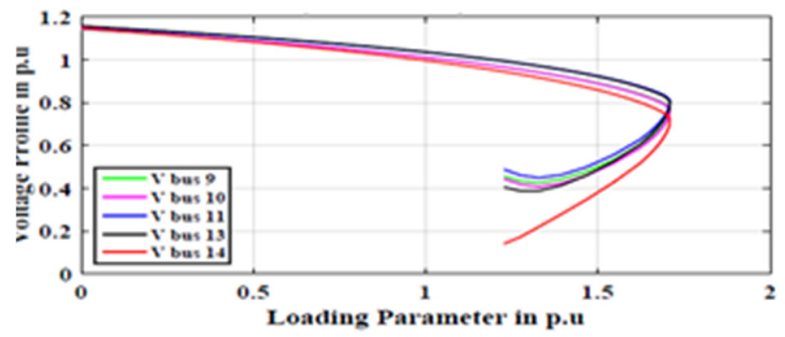

Fig. 3. Shows the IEEE 14 bus P-V curves of the basic case 
The maximum loading point for the modified system with the wind generator located at bus 14 happened at $\lambda=1.72 \mathrm{p} . u$, and this is due to the positioning of the wind generator at the weak bus. When the wind energy conversion system is connected at bus 14 , there is an increase in the maximum loading factor of the system and an improvement in the voltage levels in the weak buses as shown in Figure 4.

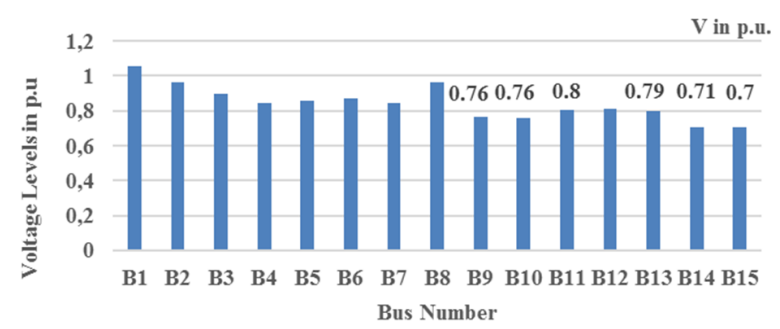

Fig. 4. The voltage levels of the integrated system using CPF method

\section{B. The Modified IEEE 14 Bus System Under 3-phase Fault}

The considered test system has been divided into three areas which are high voltage side, medium voltage side and low voltage side based on the working voltages $69 \mathrm{KV}, 18 \mathrm{KV}$, $13.8 \mathrm{KV}$ respectively of the IEEE 14 bus system. On this stage a three-phase fault has been applied on bus 1 which represents the high voltage side, bus 8 which represents the medium voltage side, and on bus 14 which represents the low voltage side. The 3-phase fault occurred at the 1.0s instant and was cleared at the $1.25 \mathrm{~s}$ instant. To examine the effects of the threephase fault on the system, the electrical variables active power, reactive power, and voltage have been monitored on the wind bus which represents bus 15. From the results shown in Figure 5, during the occurrence of the faults at bus 14 the voltage dropped from $1.045 \mathrm{p} . \mathrm{u}$ to almost $0 \mathrm{p} . \mathrm{u}$ and therefore, the acceleration of the wind rotor reduced making the transmitted active power by the wind generator to the system equal to $0 \mathrm{p} . \mathrm{u}$ as shown in Figure 6.

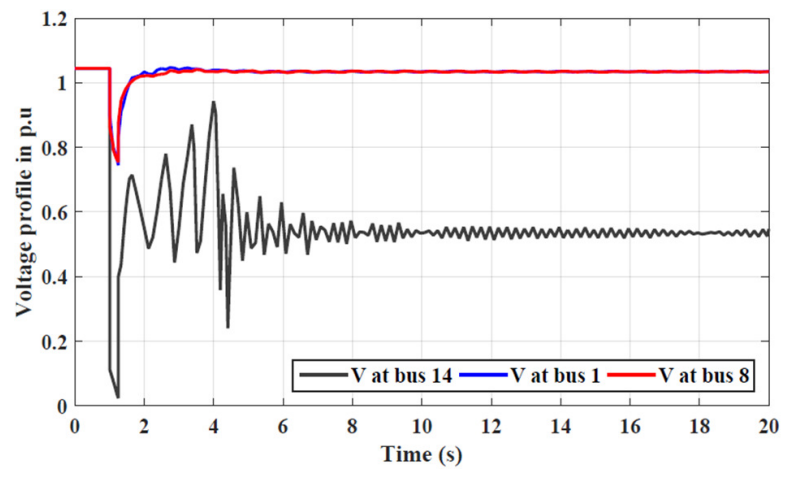

Fig. 5. Voltage profiles response at the wind bus with fault applied at bus 1 , bus 8 , and bus 14

It was noted that when the fault was cleared the system attempted to restore back to its original operating point making the SCIG wind power generator to absorb a huge reactive power amount equal to $-0.8 \mathrm{p}$.u from the distribution portion of the system as shown in Figure 7. When the fault occurred at bus 14 the wind system became unstable. This was because the reactive power demanded by the SCIG wind turbine was not enough for the rotor magnetization of the wind generator, while in the other fault cases (fault at bus 1 and bus 8) the wind system kept its stability although reactive power had been consumed.

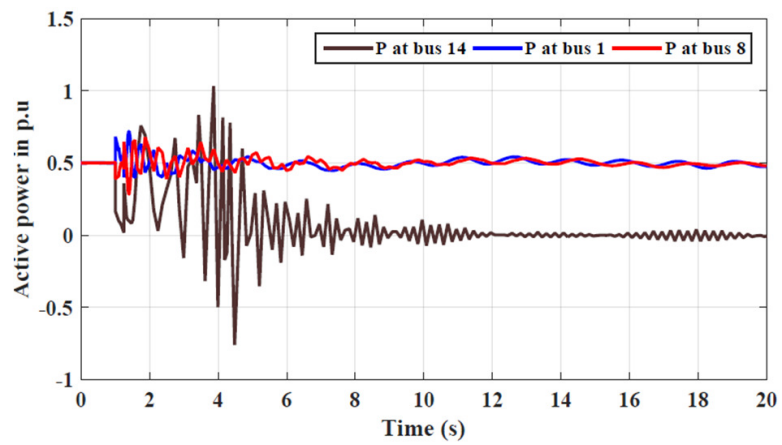

Fig. 6. Active power transmitted by a wind turbine with fault applied at bus 1 , bus 8 , and bus 14

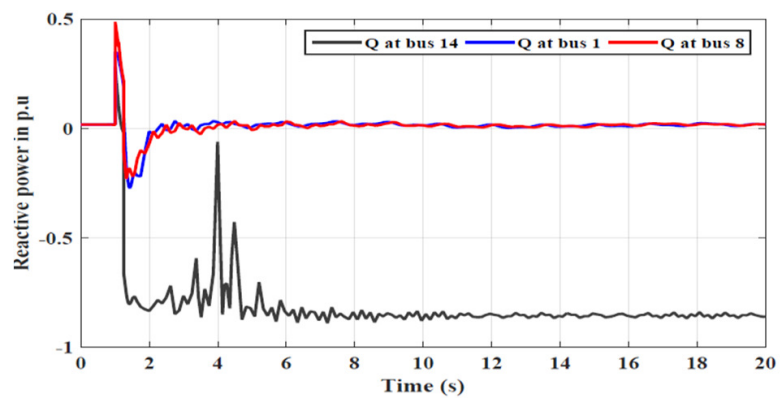

Fig. 7. Reactive power transmitted by wind turbine with fault applied at bus 1 , bus 8 , and bus 14

\section{Determination of the Weakest Lines and Buses for an Integrated System with the Wind at Bus 14}

From sub-section $B$ it is evident that the SCIG wind turbine required huge reactive power when the fault was close to the wind bus. Also, the distribution part as shown in Figure 5 describing the installed wind turbine has some nodes needing reactive power support which may lead to instability. Therefore, it is recommended to apply the VSI for the integrated IEEE 14 bus system, to determine the weakest lines and corresponding buses for reactive power support.

\section{1) Procedures of Computing the VSI}

The steps that have been followed are:

- Perform the Newton-Raphson method for the integrated IEEE 14 bus test system and obtain the load flow report.

- From load flow results and by the use of (7) and (8) the FVSI and the Lmn for all buses and lines of the system are computed.

- The reactive power at the receiving-end bus for the selected load bus progressively increases until the load flow process fails to converge to a solution. This is followed by the calculation of FVSI. 
- The line index with the highest values shall be taken out as the most significant weak line with reference to a bus.

- Another load bus is chosen and the previous procedures are repeated.

2) Calculation of FVSI and Lmn for the Integrated IEEE 14 Bus System.

Figure 8 shows the obtained values from the calculation of FVSI and Lmn.

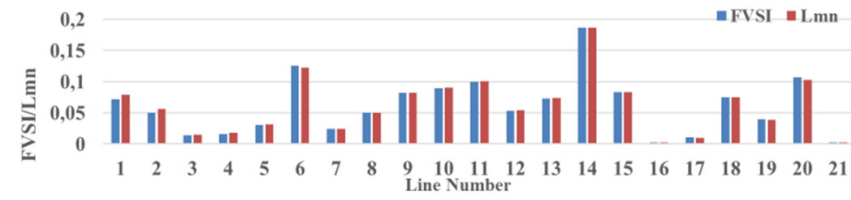

Fig. 8. Bar graph of the calculated values of FVSI, Lmn of the integrated IEEE 14 bus test system.

The modified system has 21 transmission lines, but only 15 transmission lines have been considered. This is because they connect load buses, which are line numbers $4,5,7,8,9,11,12$, $13,15,16,17,18,19,20$, and 21 . Among the considered lines, the ones with the highest values (greater or equal to 0.04 ) of FVSI and Lmn have been taken as critical lines, which are lines $8,9,11,12,13,15,18$ and 20 as shown in Figure 8.The results showed that load bus 14 is the weakest bus and exposed to voltage instability. It has the lowest maximum allowable reactive power of $63 \mathrm{MVAR}$ compared to the other load buses as shown in Figure 9. Bus 14 has three lines connected to it and the weakest line with respect to load bus 14 is the line 13-14. Hence this implies that any absorption of 63MVAR or more will tend to voltage collapse.

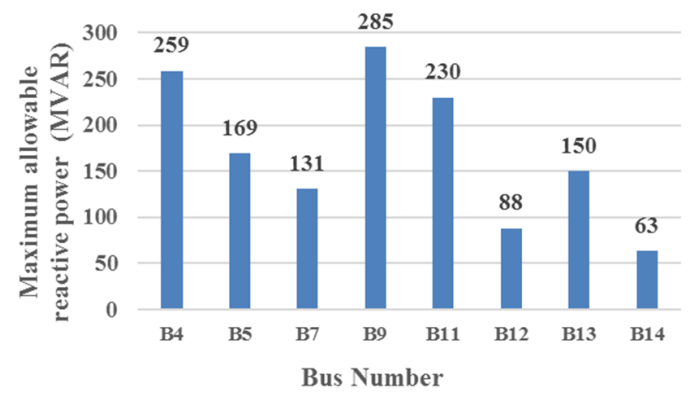

Fig. 9. Maximum allowable reactive power on load buses

\section{Comparison of the FACTS Devices Used}

At this stage, two types of FACTS devices, STATCOM and SSSC FACTS devices, were compared. By the utilization of PSAT platform, the time domain simulation (TDS) approach have been examined to evaluate the performance of FACTS when a three-phase fault occurs at bus 14 .

\section{1) Performance of STATCOM and SSSC FACTS Devices During a Three-phase Fault.}

The scenario that was discussed in sub-section B has been repeated again with the presence of 100MVA SSSC and STATCOM FACTS devices. SSSC is connected to line 20 (between bus 13 and bus 14) and STATCOM is connected to bus 14. Comparison analysis between the SSSC and
STATCOM has been made based on the responses of the electrical variables voltage, active and reactive power with respect to the considered system under three-phase faults. Figure 10 shows the voltage responses of the wind bus before and after the connection of SSSC and STATCOM FACTS devices. It is evident that the system was able to revert back to the normal operation and this is attributed to the consumed reactive power amount by SCIG wind turbine that has been generated from SSSC and STATCOM FACTS devices making the system stable. Although both types of FACTS devises performed well in the system, STATCOM settled down before SSSC. This is attributed to the effectiveness of STATCOM at low voltage levels which has made the system stability better than when using SSSC. With regards to active power response, SSSC has better performance than STATCOM as shown in Figure 11. STATCOM oscillated higher and delayed in the settlement compared to SSSC.

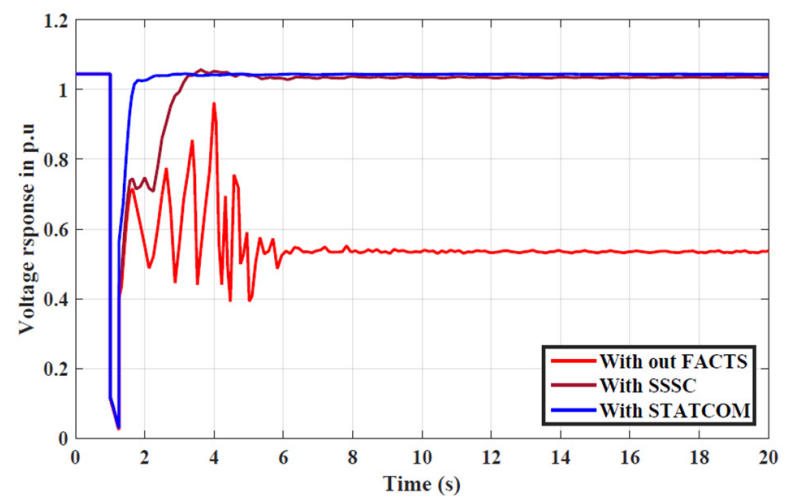

Fig. 10. Voltage responses at wind bus 15 with fault applied at bus 14

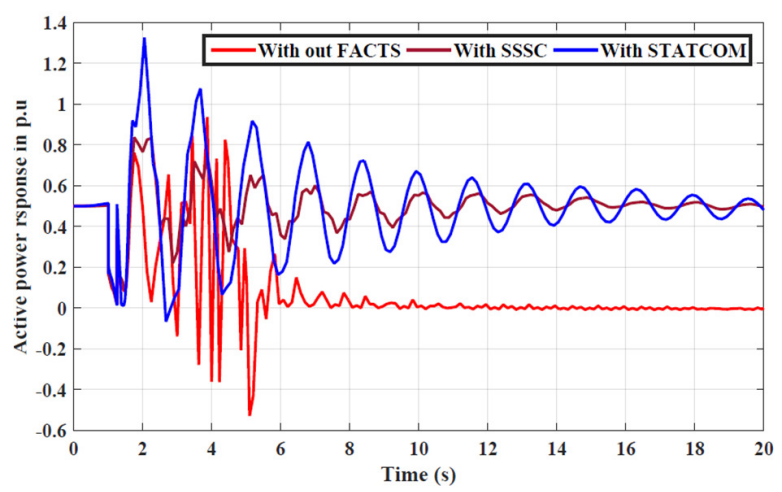

Fig. 11. Active power responses at wind bus 15 with fault applied at bus 14

Finally, the analysis was extended to the reactive power response that was delivered by both FACTS devices. Figure 12 shows the reactive power drawn by the SCIG wind turbine. As mentioned above, the instability occurred because of SCIG wind turbine reactive power absorption goes more than 63MVAR. Therefore, in SSSC and STATCOM cases even if the reactive power demand goes beyond 63MVAR these devices were able to support the excess reactive power demand which makes the system stable. STATCOM reacted faster than SSSC. Furthermore, STATCOM started to settle down before SSSC. 


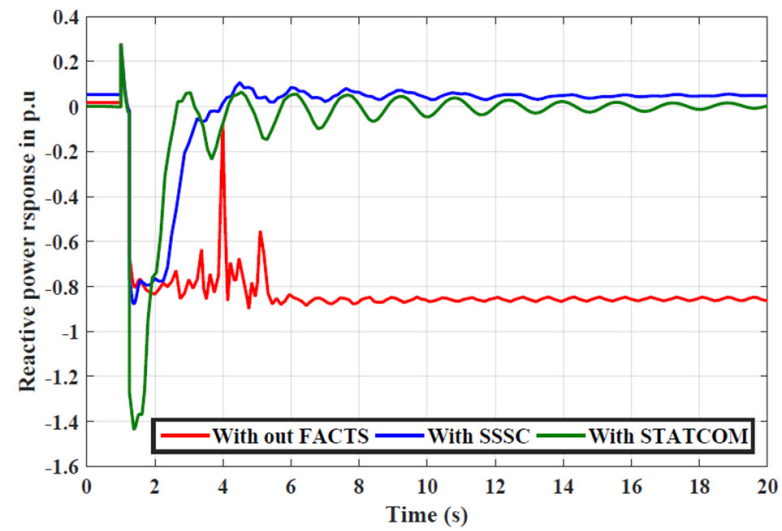

Fig. 12. Reactive power responses at wind bus 15 with fault applied at bus 14

\section{CONCLUSION}

The computation of VSI of the standard IEEE 14 bus after the integration of the SCIG wind power turbine was calculated along with the comparative investigation of STATCOM and SSSC FACTS devises. The results were drawn for simulations with the SCIG wind power turbine incorporated to the distribution network at bus 14 . There was an enhancement of the voltage levels at some load buses with a difference of $0.2 \mathrm{p} . \mathrm{u}$, and the loadability margin increased from 1.7 to 1.72 . There was also a reduction in the active and reactive electric power losses from 1.3p.u and 5.18p.u to 0.97p.u and 3.59p.u respectively. Furthermore, there was a massive reactive power amount at the time of fault occurrence. The weak parts of the system were determined and the maximum permissible reactive power for load buses was computed. To prevent voltage collapse, STATCOM and SSSC have been employed and comparatively STATCOM provided more effective outcomes than SSSC.

\section{REFERENCES}

[1] Z. H. A. Tameemi, K. M. Abuwaleda, H. M. Almukhtar, M. K. Abbas, "Voltage stability enhancement based on DG units", Electrical Engineering, Vol. 100, No. 4, pp. 2707-2716, 2018

[2] J. B. V. C. Subrahmanyam, P. A. Bandana, K. Bhanupriya, C. Shashidhar, "Renewable energy systems: Development and perspectives of a hybrid solar-wind system", Engineering, Technology \& Applied Science Research, Vol. 2, No. 1, pp. 177-181, 2012

[3] M. Benchagra, M. Hilal, Y. Errami, M. Ouassaid, M. Maaroufi, "Modeling and control of SCIG based variable-speed with power factor control", International Review on Modelling and Simulations, Vol. 4, No. 3, pp. 1007-1014, 2011

[4] D. Devaraj, R. Jeevajyothi, "Impact of Fixed and Variable Speed Wind Turbine Systems on Power System Voltage Stability Enhancement", IET Conference on Renewable Power Generation, Edinburgh, UK, September 6-8, 2011

[5] H. Li, Z. Chen, L. Han, "Comparison and Evaluation of Induction Generator Models in Wind Turbine Systems for Transient Stability of Power System", International Conference on Power System Technology, Chongqing, China, October 22-26, 2006

[6] P. Kundur, Power System Stability and Control, McGraw Hill, 1994

[7] A. Rashad, S. Kamel, F. Jurado, "Stability improvement of power systems connected with developed wind farms using SSSC controller", Ain Shams Engineering Journal, Vol. 9, No. 4, pp. 2767-2779, 2018
[8] I. N. Muisyo, K. K. Kaberere, "Utilization of FACTS Devices in Power Systems : A Review", Sustainable Research and Innovation Conference, Nairobi, Kenya, May 2-4, 2018

[9] O. L. Bekri, M. K. Fellah, "Optimal placement of wind farms for enhancing voltage stability using CPF analysis", Deuxieme Conference Internationale sur l'Electrotechnique, l'Electronique, l'Automatique et la Maintenance, November 24-25, 2015

[10] A. S. Telang, P. P. Bedekar, "Application of voltage stability indices for proper placement of STATCOM under load increase scenario", World Academy of Science, Engineering and Technology International Journal of Energy and Power Engineering, Vol. 10, No. 7, pp. 998-1003, 2016

[11] I. I. Ali, M. N. Mohsen, "Enhancement voltage stability of the iraqi power grid using shunt FACTs devices", Engineering and Technology Journal, Vol. 34, No. 13, pp. 2527-2550, 2016

[12] S. Kumar, A. Kumar, N. K. Sharma, "A novel method to investigate voltage stability of IEEE-14 bus wind integrated system using PSAT", Frontiers in Energy, pp. 1-9, 2016

[13] S. Ahsan, A. S. Siddiqui, "Dynamic compensation of real and reactive power in wind farms using STATCOM", Perspectives in Science, Vol. 8, pp. 519-521, 2016

[14] K. Bhumkittipich, C. J. Ngurn, "Study of voltage stability for $22 \mathrm{kv}$ power system connected with lamtakhong wind power plant, Thailand", Energy Procedia, Vol. 34, pp. 951-963, 2013

[15] A. Oukennou, A. Sandali, "Assessment and Analysis of Voltage Stability Indices in Electrical Network Using PSAT Software", Eighteenth International Middle East Power Systems Conference, Cairo, Egypt, December 27-29, 2016

[16] R. Jadeja, S Patel, S. K. Chauhan, "STATCOM-A preface to power quality in power systems performance", Engineering, Technology \& Applied Science Research, Vol. 6, No. 1, pp. 895-905, 2016

[17] K. R. Padiyar, Facts Controllers in Power Transmission and Distribution, New Age International Publishers, 2007 (in India)

[18] P. Anusri, K. C. S. Thampatty, "Mathematical modeling of the squirrel cage induction generator based wind farm for sub-synchronous resonance analysis", Indian Journal of Science and Technology, Vol. 9, No. 38, pp. 1-7, 2016

[19] F. Milano, "An open source power system analysis toolbox", IEEE Transactions on Power Systems, Vol. 20, No. 3, pp. 1199-1206, 2005

[20] M. Moghavvemi, F. M. Omar, "Technique for contingency monitoring and voltage collapse prediction, IEE Proceedings - Generation, Transmission and Distribution, Vol. 145, No. 6, pp. 634-640, 1998 